\title{
REVISTAMATËRIA
}

\section{Propriedades geotécnicas de um solo expansivo tratado com cal}

\section{Geotechnical properties of a lime-treated expansive soil}

\author{
Sergio Carvalho de Paiva ${ }^{1}$, Márcia Alves de Assis Lima², \\ Maria da Graça de Vasconcelos Xavier Ferreira ${ }^{1}$, \\ Silvio Romero de Melo Ferreira ${ }^{1,2}$
}

\footnotetext{
${ }^{1}$ Universidade Católica de Pernambuco, Rua do Príncipe, 526, Boa Vista, CEP 50050-900, Recife, PE, Brasil, e-mail:spaiva@unicap.br, e-mail:mgvxferreira@gmail.com

${ }^{2}$ Universidade Federal de Pernambuco, Av. Acadêmico Hélio Ramos s/n, CEP 50740-530, Recife, PE, Brasil, e-mail: marcia_alima@yahoo.com.br; sr.mf@hotmail.com
}

\section{RESUMO}

Argilas expansivas são consideradas como depósitos problemáticos para obras de infraestrutura porque podem causar danos socioeconômicos e ambientais, uma vez que são susceptíveis à mudança de volume devido à variação sazonal da umidade e temperatura. A estabilização da argila expansiva é de interesse para qualquer edificação. As técnicas de estabilização podem ser mecânicas ou químicas. A cal é um agente estabilizante. Ensaios de laboratório foram realizados com o objetivo de analisar o efeito da interação da cal com um solo expansivo de Ipojuca/PE, quando é adicionado cal nas proporções de $1 \%$ a $11 \%$ em peso seco. Foram investigadas as características físicas, químicas, mineralógicas, a expansão livre e a tensão de expansão do solo natural e na mistura solo-cal. Os resultados indicam que o solo tem alta expansividade, podendo causar danos às edificações levando à demolição, principalmente as de pequeno porte. A adição de cal ao solo causou uma agregação ou floculação das partículas originais e a redução no índice de plasticidade. O percentual de 11\% de cal hidratada reduziu a expansão livre e tensão de expansão a valores nulos. Isto é atribuído à capacidade de cimentação do solo tratado com a cal que reduz a tendência de absorção de água das argilas saturadas com cálcio.

Palavras-chave: Solo expansivo, métodos de investigação, solo-cal.

\begin{abstract}
Expansive clays are problematic deposits for infrastructure projects because they can cause socio-economic and environmental damage, since they are susceptible to change in volume due to seasonal variation in humidity and temperature. The stabilization of expansive clay is of interest to any construction. The stabilization techniques may be mechanical or chemical. Hydrated lime is a stabilizing agent. Laboratory tests were conducted in order to analyze the effect of the interaction of hydrated lime with expansive soils of Ipojuca County / PE, when hydrated lime was added to it in proportions of $1 \%$ to $11 \%$ by dry weight. The physical, chemical and mineralogical characterizations were performed as well as the free swell and the expansion stress of natural soil and soil-lime mixture. The results indicate that the soil has high expansiveness and may cause damage to buildings leading to demolition, especially the smaller ones. The addition of hydrated lime to the soil caused an original aggregation or flocculation of particles and the decrease in plasticity index. The percentage of $11 \%$ of hydrated lime added to the expansive soil reduced the free swell and expansion stress to null values. This is attributed to the cementing capacity of the soil treated with lime which reduces the tendency of water absorption by the calcium saturated clay.
\end{abstract}

Keywords: Expansive soil, research methods, soil-lime.

\section{INTRODUÇÃO}

A construção de obras de engenharia civil em solos que apresentam instabilidade volumétrica, quando umedecidos, pode causar sérios problemas. Em solos expansivos, em campo, observam-se fissuras ou fendas ca- 
racterísticas, nas estações secas. Já nas edificações, fissuras diagonais embaixo das janelas e acima das portas, (Figura 1), ondulações e rupturas nos pavimentos, fissuras generalizadas longitudinais e transversais junto a bueiros, etc.

Nos EUA, danos causados pelos solos expansivos em edifícios e infraestruturas excede 15 milhões de dólares anualmente. A Sociedade Americana de Engenheiros Civil estima que uma em cada quatro casas tem alguns danos causados por solos expansivos. Em um ano típico, solos expansivos podem causar maior perda financeira para os proprietários do que danos causados por tremores de terra, inundações, tornados e furações combinados [1]. A Associação de Seguradoras Britânicas estimou que o custo médio com solo expansivo para a indústria de seguros está em mais de 400 milhões de libras por ano [2]]. Na Espanha o custo mínimo com a recuperação dos danos causados por solos expansivos é cerca de 1 bilhão de pesetas/ano [3]. No Brasil não se têm dados específicos dos custos com danos causados por esses solos, quando inundados.
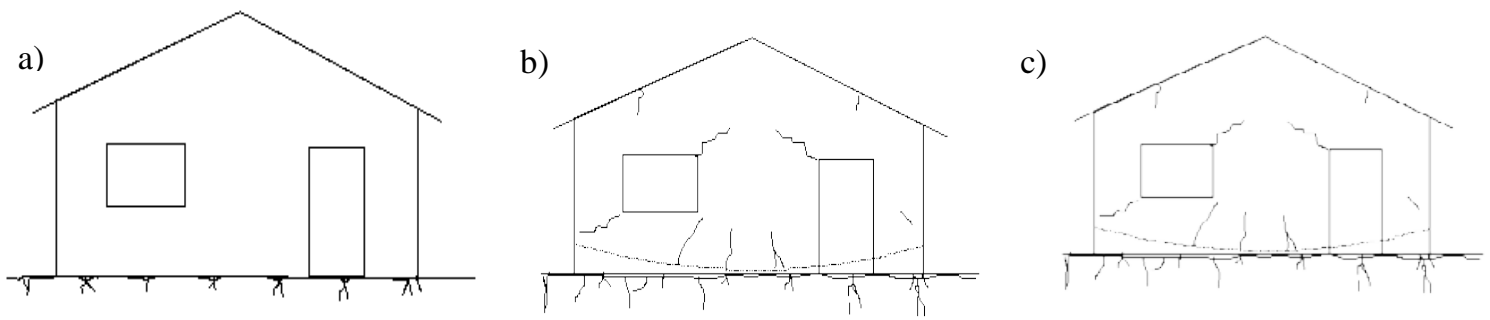

Figura 1: Linhas de fendilhamento em edificações de baixa altura, de forma esquemática a) Estado inicial b) Expansão no centro da edificação e retração na periferia c) Expansão nos lados da edificação, [3]

Como se constata, a ocorrência de problemas de engenharia associados aos solos expansivos é registrada em diversos continentes e países. Na África (Angola, Etiópia, Gana, Quênia, Nigéria, África do Sul, e Tanzânia), Américas (Canadá, Argentina, Peru, Venezuela, Estados Unidos), Austrália (Ilhas Rainhas, Austrália do Sul e Victoria), Eurásia (China, Índia, Romênia, Espanha, Reino Unido) e Oriente Médio - Israel, Jordânia e Arábia Saudita [4].

No Brasil, os solos expansivos já foram identificados nas regiões Sul, Centro Sul, Norte e Nordeste, [5, 6, 7, 8, 10]. Em Pernambuco, há registros nos municípios de: Afrânio, Petrolina, Cedro, Cabrobó, Salgueiro, Floresta, Serra Talhada, Petrolândia, Inajá, Ibimirim, Carnaíba, Nova Cruz, Paulista, Olinda, Recife e Cabo de Santo Agostinho. O Sistema de Informações Geográficas dos Solos Expansivos e Colapsíveis do Estado de Pernambuco (SIGSEC-PE) indicou uma suscetibilidade de ocorrência alta em 12,5\% da área do Estado, média em $38,7 \%$ e baixa em $45,2 \%$, [1, 12$]$.

Vários são os tipos de solos sujeitos ao fenômeno de expansão. Entre eles podem se destacar os oriundos de rochas ígneas, basaltos, diabásios e gabros e os de rochas sedimentares, folhelhos, margas e calcários, todos com filossilicatos expansivos na fração argila [4, 6,7, 8, 10]

Para um solo ser expansivo, depende, primariamente, do filossilicato existente na fração argila, uma vez que nem todos experimentam modificações volumétricas, com variação de umidade. A instabilidade pode ser especialmente importante nas vermiculitas e esmectitas, em especial na montmorilonita e nos interestratificados regulares ou irregulares onde estes minerais estão presentes) [3, 8, 10].

Dois requisitos básicos, um intrínseco e outro extrínseco, são necessários para um solo exibir expansividade. O intrínseco está relacionado com a composição mineralógica, textura e estrutura. Esses parâmetros controlam, em nível microescalar, mecanismos que produzem a instabilidade volumétrica do solo. O extrínseco está relacionado com a climatologia, a hidrogeologia, a vegetação e a ocupação antrópica que são capazes de transferir a umidade de um ponto a outro do terreno.

Vários estudos foram realizados e descritos na literatura para explicar as melhorias nas propriedades mecânicas e hidráulicas de solo expansivo, devido à adição de cal e outros estabilizadores, principalmente a partir de um ponto de vista macroscópico. São analisadas as mudanças associadas aos valores dos limites de plasticidade e liquidez e propriedades tais como a variação do volume (isto é, a tensão de expansão e a expansão livre, resistência ao corte e o coeficiente de permeabilidade [13, 14, 15].

As melhorias das propriedades geotécnicas de solos estabilizadas com cal são atribuídas a quatro reações básicas: troca catiônica, floculação e aglomeração, carbonatação da cal e, finalmente, à reação pozolânica [16, 17, 18, 19, 20, 21]. Há consenso na literatura sobre os primeiros três tipos de reações como reações instantâneas. No entanto, a reação pozolânica, que é considerada como o parâmetro mais relevante na estabi- 
lização solo-cal, depende do tempo. A reação pozolânica surge em um ambiente marcadamente alcalino (com $\mathrm{pH} \geq 12$ ) produzido pela adição de uma quantidade mínima de cal ao solo expansivo. É este ambiente que se crê ser responsável pela dissolução lenta dos constituintes aluminossilicato de argila (octahedral e folhas tetraédricas). Estes componentes reagem com $\mathrm{Ca}^{2+}$ da cal e precipitam produtos cimentícios hidratados que unem as partículas adjacentes do solo [22].

Diversos projetos de infraestrutura encontram-se em desenvolvimento ou serão implantados no país, em especial no Nordeste, e vários deles serão executados em solos expansivos. O presente artigo tem por objetivo analisar o efeito da interação da cal com solos expansivos no município de Ipojuca-PE, utilizando mistura do solo, em peso, com 1\%, 3\%, 5\%, 7\%, 9\% e $11 \%$ de cal.

\section{MATERIAIS E MÉTODOS}

O programa de investigação geotécnica realizado para analisar o comportamento de solo expansivo de Ipojuca - PE constou da coleta de amostras deformadas e indeformadas do tipo bloco e realização de ensaios de laboratório no solo, na cal e nas misturas solo-cal nas proporções em peso seco 1\%, 3\%, 5\%, 7\%, 9\% e 11\%.

A cal hidratada utilizada foi classificada segundo a ABNT [23]. Foram realizadas as determinações de umidade, perda ao fogo, óxido de silício, óxido férrico, óxido de cálcio, óxido de magnésio e massa específica obedecendo as recomendações da ABNT [24], retenção de água de acordo com a ABNT [25] e a finura pela ABNT [26].

Na preparação das misturas solo-cal, inicialmente, procurou-se definir o menor teor de cal que a estabilizasse, com o pH de 12,42, pelo critério de Eades e Grim [16]. Com o valor do teor de cal definido (7\%) foram preparadas as misturas para a realização dos ensaios de caracterização física, química, mineralógica, expansão livre e tensão de expansão; tomou-se o peso seco da amostra do solo e foi adicionado cal em teores de $1 \%, 3 \%, 5 \%$ e $7 \%$, em peso. A mistura (solo-cal) foi homogeneizada e os ensaios foram realizados após 1 hora, com exceção dos ensaios químicos que também foram realizados após 120 dias. Os métodos utilizados para o solo foram os mesmos para a mistura solo-cal.

A preparação das amostras do solo seguiu as recomendações da ABNT [27], ABNT [28] e os ensaios de caracterização física foram realizados a partir de: determinação do Limite de Liquidez ABNT [29], determinação do Limite de Plasticidade ABNT [30], determinação da Massa Específica ABNT [31] e análise Granulométrica ABNT [32]. Para melhor avaliar a influência da adição da cal na granulometria foram realizados ensaios por difração a laser para dimensões $<0,64 \mathrm{~mm}$.

A caracterização química do solo foi realizada conforme a metodologia do Manual de Métodos de Análise de Solos da Embrapa [33] e os cálculos de acordo com o novo sistema de classificação de solos da Embrapa [34]. A composição química quantitativa do solo, expressa em óxidos, foi obtida através de espectrometria de fluorescência de raios-X (FRX) em amostras fundidas, com determinação de teores dos dez óxidos de maior abundância: $\mathrm{SiO}_{2}, \mathrm{Al}_{2} \mathrm{O}_{3}, \mathrm{Fe}_{2} \mathrm{O}_{3}, \mathrm{CaO}, \mathrm{MnO}, \mathrm{MgO}, \mathrm{Na}_{2} \mathrm{O}, \mathrm{K}_{2} \mathrm{O}, \mathrm{TiO}_{2}$ e $\mathrm{P}_{2} \mathrm{O}_{5}$. Uma porção de cada amostra foi colocada em estufa para secar a $110^{\circ} \mathrm{C}$ e então levada a uma mufla, a $1000^{\circ} \mathrm{C}$ por 2 horas, para a determinação de perda ao fogo. Foram feitas pérolas fundidas usando tetraborato de lítio como fundente. As pérolas foram analisadas em espectrômetro de fluorescência de raios X Rigaku modelo RIX 3000, equipado com tubo de Rh, pelo método de curvas de calibração, que foram construídas com materiais de referências internacionais.

A mineralogia foi determinada por Termogravimetria (TG), Termogravimetria Derivada (DTG) e Difratometria de Raio X. Na Termogravimetria (TG) e Termogravimetria Derivada (DTG) foi utilizado o equipamento modelo NETZSCH STA 409PC com atmosfera de Nitrogênio 5,0 analítico e taxa de aquecimento de $10{ }^{\circ} \mathrm{C} /$ minuto, até uma temperatura máxima de $1000{ }^{\circ} \mathrm{C}$. No cadinho, $1,0 \mathrm{~g}$ do solo não recebeu nenhum tratamento prévio. Os resultados foram analisados com auxílio do programa NETZSCH Proteus - Termal Analysis Version 4.2.1.

A difração de raio-X foi realizada na argila total $(<0,002 \mathrm{~mm})$, depois de separada por sedimentação. Foram preparadas três lâminas: duas saturadas com potássio, uma das quais foi levada ao raio-X à temperatura ambiente $\left(25^{\circ} \mathrm{C}\right)$ e a outra aquecida a $550{ }^{\circ} \mathrm{C}$ por duas horas, e a terceira lâmina, saturada com magnésio e impregnada com glicerol a $10 \%$. As lâminas foram preparadas com orientação paralela, de acordo com [35]. Os dados foram coletados empregando-se um difratômetro Shimadzu XRD-6000 com radiação CuKT, tensão de $40 \mathrm{KV}$, corrente de $30 \mathrm{~mA}$, tamanho do passo de 0,020 2U e tempo por passo de 1,000s, com velocidade de varredura de $2^{\circ}(2 \mathrm{U}) / \mathrm{min}$, com ângulo $2 \mathrm{U}$ percorrido de 2 a $42^{\circ}$.

A contextura (microestrutura) do solo foi observada através de Microscopia Eletrônica de Varredura MEV a partir das amostras dos ensaios, coletadas, cuidadosamente, e colocadas para secar ao ar. Foram mol- 
dados três corpos de prova, de formato prismático, com base de $9,8 \mathrm{~mm}$ e altura de $8 \mathrm{~mm}$, tendo-se o cuidado para que nenhum instrumento cortante ou pontiagudo tocasse na superfície de observação, utilizando a mesma técnica, descrita por [36]. O suporte de alumínio, com as amostras, foi colocado em uma campânula de vácuo do tipo Fine Coat, Ion Sputter JfC-1100 da marca JEOL e metalizado com ouro por meio de evaporação. O equipamento JSM T200 Scanning Microscope de marca JOEL, com máquina fotográfica acoplada, e poder de resolução bem ampliado permitiu aumentos de 40.000 vezes.

Os ensaios de expansão livre foram realizados em células edométricas convencionais. Amostras indeformadas dos solos foram talhadas em anéis de aço inoxidável de altura 20,00 mm e diâmetro de 71,3 mm e submetidas a pequenas tensões de 1,0 e $10,0 \mathrm{kPa}$.

A tensão de expansão foi determinada por três métodos diferentes: 1 - Carregamento após expansão com diferentes tensões verticais de consolidação, 2 - Expansão e colapso sob tensão e 3 - Volume constante. No Método 1 (Carregamento após expansão com diferentes tensões verticais de consolidação) a amostra foi levada a expandir, sendo inundada. A seguir, cada corpo de prova foi submetido a diferentes tensões verticais de consolidação (10, 40, $80 \mathrm{kPa})$, que eram aplicadas por estágios, tal como descrito anteriormente. As deformações foram medidas em intervalos de tempo, até a estabilização ser alcançada. Após a estabilização foram consolidadas sob um aumento de tensão. A tensão de expansão é a média das tensões obtidas em cada corpo de prova, correspondente àquela em que a amostra retorna a altura inicial. A trajetória de tensão, após a inundação, foi iniciada com a sobrecarga de inundação e aplicada por estágio com $\Delta \sigma / \sigma=1$ até a tensão de 640 kPa. O tempo de duração de cada estágio foi de 24 horas. No Método 2 (Expansão e colapso sob tensão) a amostra de solo foi colocada na célula e ajustada à prensa, em seguida cada corpo de prova foi submetido a uma das seguintes tensões: 10, 40, $80 \mathrm{kPa}$ que foram aplicadas por estágios, sendo o corpo de prova, em seguida, inundado e medidas as deformações ocorridas. No Método 3 (Volume constante) a amostra foi inundada e à medida que o solo aumentava de volume, foi colocada uma sobrecarga para impedir esta variação. Nas primeiras horas de ensaio permitiu-se uma pequena expansão de $0,02 \mathrm{~mm}$ para a aplicação da sobrecarga. A soma das sobrecargas corresponde a uma tensão, que é a tensão de expansão do solo a volume constante. Os valores dos potenciais de expansão (SP), obtidos por meio dos ensaios edométricos simples, foram calculados pela Equação 1.

$$
S P(\%)=\Delta \mathrm{h} \times 100 / \mathrm{hi}
$$

em que: $\Delta$ h é a variação da altura do corpo de prova devido à inundação e hi é a altura do corpo de prova antes da inundação.

A expansão livre e a tensão de expansão determinadas pelo método volume constante nas misturas solo-cal foram avaliadas em amostras compactadas na umidade ótima e peso específico aparente seco máximo. Considerando a mistura solo-cal com adição de 7\% de cal, houve expansão. Foram realizados outros ensaios com teores maiores de cal (9\% e 11\%) até a mistura solo-cal não mais expandir quando inundada.

\section{RESULTADOS E DISCUSSÕES}

\subsection{Caracterização da Cal}

A Tabela 1 traz a análise da cal. Todos os parâmetros analisados apresentam resultados compatíveis com uma cal de ótima qualidade CHI segundo a ABNT [23]. A curva de distribuição é bastante uniforme, onde 80\% dos grãos encontram-se entre 0,002 mm e 0,02 mm, Figura 2.

\subsection{Caracterização Física do Solo e das Misturas Solo-cal}

A distribuição granulométrica do solo expansivo de Ipojuca - PE é apresentada nas Figuras 2 e 3. É constituída de $16 \%$ de areia, $17 \%$ de silte e $67 \%$ de argila, Tabela 2 . O peso específico real dos grãos é de 26,26 $\mathrm{kN} / \mathrm{m}^{3}$. Apresenta $\mathrm{WL}=81 \%$ e IP $=37 \%$, tem plasticidade média e alta atividade $(\mathrm{Ia}=\mathrm{IP} /<0,0002 \mathrm{~mm}) \mathrm{se}$ gundo o critério de [37]. Tem potencial de expansão muito alto pelos critérios de [38, 39].

Com a adição da cal hidratada ao solo natural há um aumento da fração silte com consequente diminuição da fração argila (Tabela 2). A relação silte/argila aumentou de 0,25 para 0,69. Isto se deve à capacidade da cal em flocular e aglomerar as partículas devido ao aumento da concentração eletrolítica e redução da espessura da camada dupla difusa, visto que a cal possibilita um equilíbrio da partícula de argila. As curvas de distribuição de partículas, do solo natural e da mistura solo-cal (Figura 2), deslocam-se para o lado direito, demonstrando que houve um aumento no tamanho das partículas (silte e areia). 
Tabela 1: Resultados das análises da cal.

\begin{tabular}{l|c|c}
\hline \multicolumn{1}{c|}{ DETERMINAÇÕES } & UNIDADE & RESULTADO \\
\hline Umidade & $\%$ & 1,31 \\
\hline Perda ao fogo & $\%$ & 24,23 \\
\hline Óxido férrico $\left(\mathrm{Fe}_{2} \mathrm{O}_{3}\right)$ & $\%$ & 0,22 \\
\hline Óxido de cálcio total $\left(\mathrm{CaO}_{\mathrm{T}}\right)$ & $\%$ & 66,93 \\
\hline Óxido de cálcio disponível $\left(\mathrm{CaO}_{\mathrm{D}}\right)$ & $\%$ & 58,49 \\
\hline Anidrido carbônico $\left(\mathrm{CO}_{2}\right)$ & $\%$ & 4,09 \\
\hline Massa específica & $\mathrm{g} / \mathrm{mL}$ & 0,445 \\
\hline Finura peneira $30-0,600 \mathrm{~mm}$ & $\%$ & 0,10 \\
\hline Finura peneira $200-0,075 \mathrm{~mm}$ & $\%$ & 0,13 \\
\hline Retenção de água & $\%$ & 87 \\
\hline
\end{tabular}

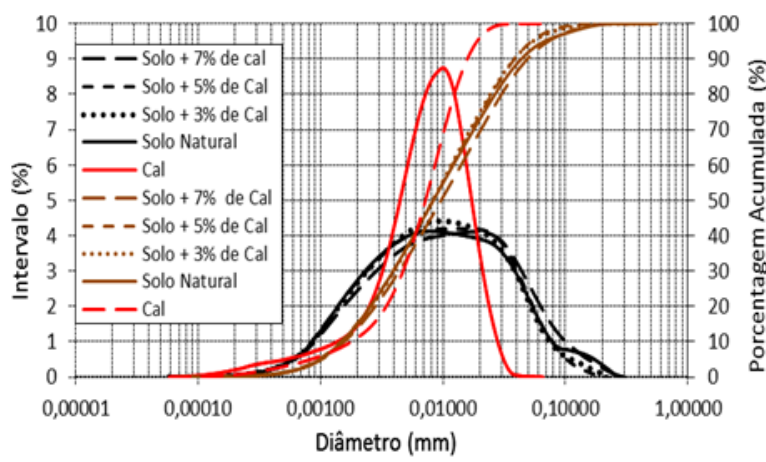

Figura 2: Distribuição dos tamanhos das partículas do solo obtida por difração a laser.

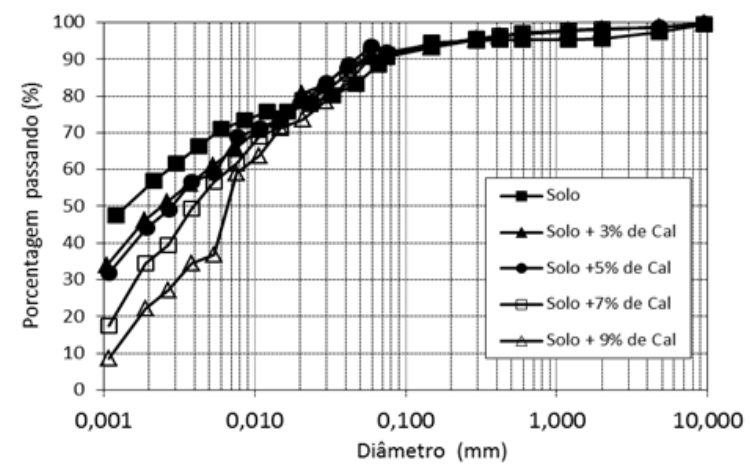

Figura 3: Curvas granulométricas do solo e misturas solocal.

Tabela 2: Caracterização física dos solos e da mistura solo-cal.

\begin{tabular}{l|c|c|c|c|c|c}
\hline $\begin{array}{c}\text { CARACTERIZAÇÃO } \\
\text { FÍSICA \% }\end{array}$ & SOLO & $\begin{array}{c}\text { SOLO+ 1\% } \\
\text { DE CAL }\end{array}$ & $\begin{array}{c}\text { SOLO+ 3\% } \\
\text { DE CAL }\end{array}$ & $\begin{array}{c}\text { SOLO+ 5\% } \\
\text { DE CAL }\end{array}$ & $\begin{array}{c}\text { SOLO+ 7\% } \\
\text { DE CAL }\end{array}$ & $\begin{array}{c}\text { SOLO+ 9\% } \\
\text { DE CAL }\end{array}$ \\
\hline Pedregulho & 0 & 0 & 2 & 2 & 2 & 1 \\
\hline Areia & 16 & - & 8 & 4 & 7 & 8 \\
\hline Silte & 17 & - & 29 & 35 & 34 & 54 \\
\hline Argila & 67 & - & 61 & 59 & 57 & 37 \\
\hline Relação Silte/Argila & 25 & - & 48 & 59 & 60 & 69 \\
\hline \% $<0,002$ mm & 57 & 46 & 44 & 39 & 27 & 27 \\
\hline IP & 81 & 93 & 95 & 93 & 95 & - \\
\hline
\end{tabular}

A adição de cal ao solo de Ipojuca - PE elevou os valores do limite de liquidez na mistura solo-cal em menor intensidade do que o acréscimo nos valores do limite de plasticidade, indicando redução do índice de plasticidade, Figura 4. Resultados semelhantes foram obtidos por [19, 21]. Brandl [13] atribuiu que as rápidas mudanças nos valores dos limites de Atterberg com adição de cal, devem-se as transformações estruturais e floculação do material. As alterações nos limites de consistência são consequência do fornecimento de elétrons para o equilíbrio das cargas. A cal supre a deficiência por carga elétrica positiva, diminui a afinidade do mineral expansivo por água e outros íons, o que diminui a expansão e altera a plasticidade do solo.

O acréscimo de cal ao solo reduziu o valor do percentual de água no extrato de saturação na mistura solo-cal até valores de 3\% de cal, Figura 4. Para os valores superiores a 3\% de cal adicionada ao solo os valores dos percentuais de água no extrato de saturação não se alteraram permanecendo praticamente constante.

A Figura 5 mostra as curvas de compactação do solo e das misturas solo-cal. As curvas de compacta- 
ção das misturas solo-cal apresentam um único pico, ao contrário do solo natural que apresenta dois picos, frequentes em solos expansivos como discutido por [36]. As misturas solo-cal apresentam uma tendência de acréscimo do peso específico aparente máximo quando comparadas com o solo natural, para uma mesma energia de compactação, Tabela 3. Barbosa [21], verificou em um solo de Cabrobó-PE que há uma diminuição no $\gamma \mathrm{d}_{\max }$ e $\mathrm{W}_{\text {ot }}$ até $5 \%$ de cal e depois cresce.

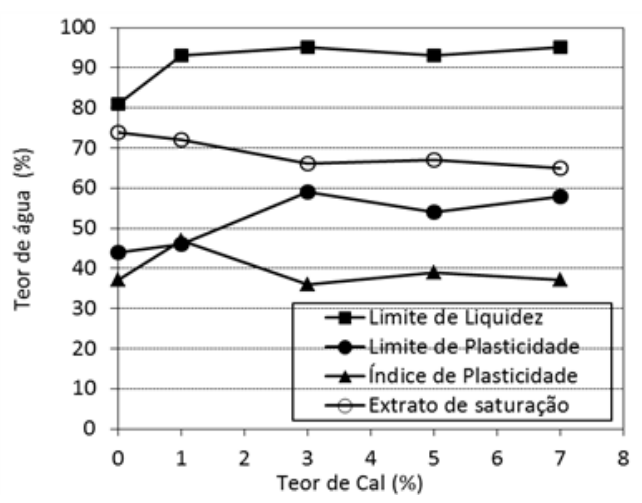

Figura 4: Variação dos Limites de Liquidez e Plasticidade, Índice de Plasticidade e Teor de água no extrato de saturação no solo e nas misturas solo-cal.

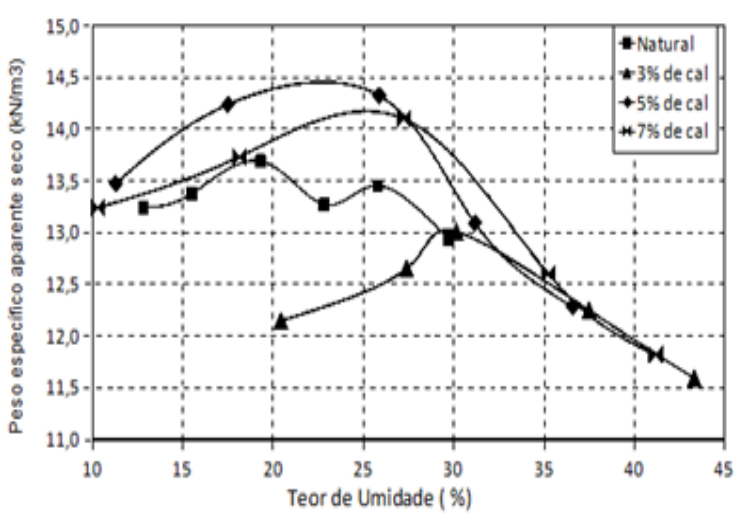

Figura 5: Curva de compactação do solo e da mistura solo-cal.

Tabela 3: Caracterização física do solo e das misturas solo-cal.

\begin{tabular}{l|c|c}
\hline \multicolumn{1}{c|}{ AMOSTRA } & $\begin{array}{c}\text { PESO ESPECÍFICO APARENTE SECO } \\
\text { MÁXIMO (KN/m } \mathbf{~})\end{array}$ & UMIDADE ÓTIMA (\%) \\
\hline Solo & 13,45 & 25,78 \\
\hline Solo + 3\% de cal & 13,01 & 30,14 \\
\hline Solo + 5\% de cal & 14,32 & 25,86 \\
\hline Solo + 7\% de cal & 14,10 & 27,21 \\
\hline
\end{tabular}

\subsection{Caracterização Química}

A Tabela 4 apresenta os resultados da caracterização química do solo e das misturas solo-cal. No solo natural o grau de saturação por base, valor V, é superior a 50\%, sendo um solo eutrófico (fértil com reservas de nutrientes). A Capacidade de Troca Catiônica é alta (valor T = CTC > $27 \mathrm{cmolc} / \mathrm{kg}$ ). O valor de saturação com sódio $(100 \mathrm{Na}+/ \mathrm{T})$ é baixo. A condutividade elétrica do extrato de saturação é alta $(115 \mu \mathrm{S})$ indicando que o solo é o salino $(>7 \mu \mathrm{S})$. O valor da matéria orgânica obtida a partir do carbono orgânico é baixo (0,02\%).

O solo é moderadamente ácido $(5<\mathrm{pH}<5,9)$ e a adição da cal torna a mistura solo-cal com alcalinidade muito forte ( $\mathrm{pH}>10,5)$. A adição de $7 \%$ elevou o valor do $\mathrm{pH}$ a 12,44, superior ao valor de 12,42 sugerido por [16] para a estabilização de solo expansivo. Segundo [39] um valor elevado de pH favorece o desenvolvimento das reações de troca de cátions e floculação, responsáveis pela melhoria da trabalhabilidade das misturas de solo-cal. A permanência de um valor elevado de $\mathrm{pH}$ favorece a ocorrência das reações pozolânicas, responsáveis pelo ganho de resistência dessas misturas ao longo do tempo. Os valores do pH da mistura solo-cal determinados para um tempo de cura de 120 dias são superiores, em média 11,21\%, aos valores obtidos para um tempo de cura de uma hora, Figura 6a. 
Tabela 4: Caracterização Química dos solos e das misturas solo-cal.

\begin{tabular}{|c|c|c|c|c|c|c|c|c|c|c|c|}
\hline \multirow[t]{2}{*}{$\begin{array}{c}\text { SOLO e } \\
\text { MISTURA } \\
\text { SOLO- CAL }\end{array}$} & \multirow{2}{*}{$\begin{array}{c}\mathbf{p H} \\
\mathrm{H}_{2} \mathrm{O}\end{array}$} & $\mathrm{Na}^{+}$ & $\mathbf{K}^{+}$ & $\mathbf{C a}^{2+}$ & $\mathbf{M g}^{2+}$ & $\mathbf{A l}^{3+}$ & $\mathbf{H}^{+}$ & S & $\begin{array}{c}\text { CTC } \\
\mathbf{T} \\
\end{array}$ & $\mathbf{v}$ & $100 \frac{\mathrm{Na}^{+}}{\mathrm{T}}$ \\
\hline & & \multicolumn{10}{|c|}{------------------------ cmol } \\
\hline Solo & 5,55 & 0,22 & 0,44 & 26,00 & 2,40 & 7,80 & 4,50 & 29,06 & 36,86 & 78,80 & 0,60 \\
\hline \multicolumn{12}{|c|}{ Após uma hora da mistura } \\
\hline Solo $+1 \%$ Cal & 7,80 & 0,40 & 0,50 & 32,7 & 2,80 & 0 & 0 & 36,40 & 36,40 & 100 & 1,10 \\
\hline Solo + 3\% Cal & 11,47 & 0,35 & 0,30 & 43,2 & 3,00 & 0 & 0 & 46,85 & 46,85 & 100 & 0,75 \\
\hline Solo + 5\% Cal & 12,29 & 0,35 & 0,30 & 57,9 & 3,90 & 0 & 0 & 62,45 & 62,45 & 100 & 0,55 \\
\hline Solo + 7\% Cal & 12,44 & 0,35 & 0,30 & 83,8 & 4,20 & 0 & 0 & 88,65 & 88,65 & 100 & 0,39 \\
\hline \multicolumn{12}{|c|}{ Após 120 dias de cura } \\
\hline Solo + 1\% Cal & 8,51 & 0,61 & 0,37 & 30,00 & 9,20 & 0 & 0 & 40,18 & 40,18 & 100 & 1,52 \\
\hline Solo + 3\% Cal & 13,04 & 0,38 & 0,22 & 33,20 & 6,80 & 0 & 0 & 40,60 & 40,60 & 100 & 0,93 \\
\hline Solo + 5\% Cal & 13,61 & 0,38 & 0,18 & 34,50 & 9,10 & 0 & 0 & 44,16 & 44,16 & 100 & 0,86 \\
\hline Solo + 7\% Cal & 13,93 & 0,38 & 0,22 & 35,20 & 6,40 & 0 & 0 & 42,20 & 42,20 & 100 & 0,90 \\
\hline
\end{tabular}

Houve um aumento da CTC do solo quando o teor de cal cresceu com o tempo de cura de 1h. Quando o tempo de cura foi de 120 dias, a CTC praticamente ficou constante com valor médio de 41,79 cmolc/kg. Entretanto, estes valores são inferiores aos obtidos quando o tempo de cura foi de uma hora, Figura 6-b. Quando o solo é misturado à cal, acontece uma interação química dos elementos da cal com o argilomineral, sendo imprescindível um tempo de cura entre as misturas para que ocorra uma completa interação entre as partículas, possibilitando a cimentação e a estabilização do solo.

Como era previsto, o óxido de silício prevalece sobre o óxido de alumínio e sobre o óxido de ferro, (Tabela 5) e a adição de cal ao solo causa redução dos óxidos de silício, alumínio, ferro, sódio, potássio e no dióxido de titânio e acréscimo dos óxidos de magnésio e cálcio. Os valores do óxido de cálcio determinados segundo as recomendações da norma ABNT [24], Tabela 1, e pela técnica analítica de espectrometria de fluorescência de raio-X, Tabela 5, são próximos.
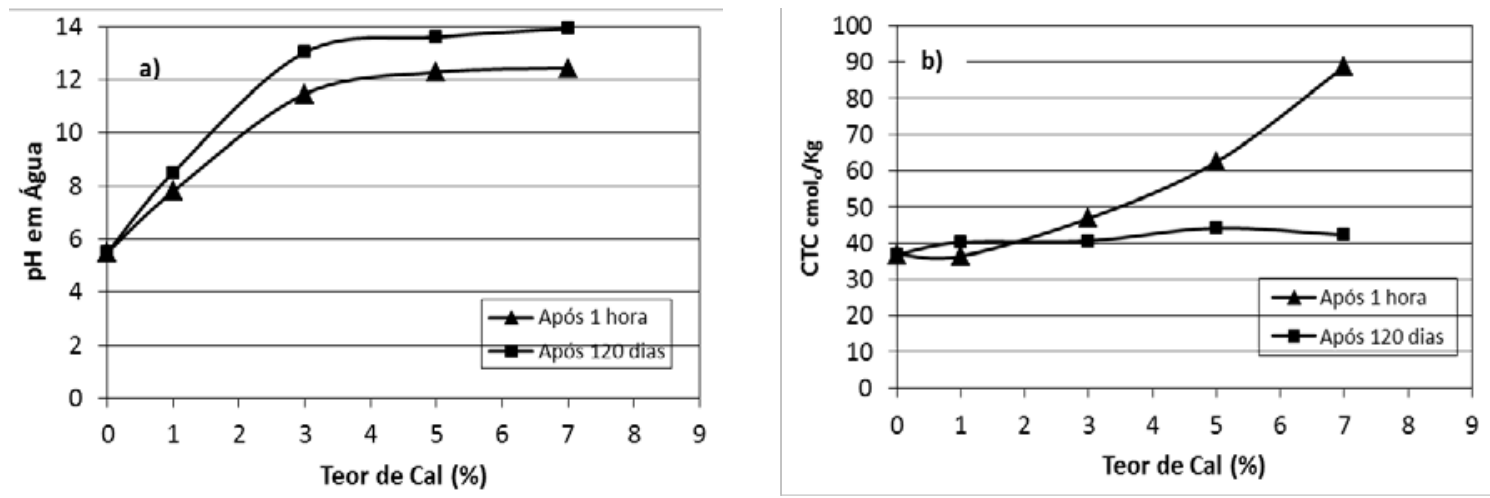

Figura 6: Variação do pH e CTC com teor de cal, a) pH b) Capacidade de Troca de Cátions.

\subsection{Caracterização Microestrutural}

A Figura 7 mostra a contextura (microestrutura) do solo e das misturas solo-cal compactadas na umidade ótima e peso específico aparente seco máximo. No solo (Figura 7-a) há uma macroestrutura prismática formada por fortes e grandes blocos angulares e subangulares. A microestrutura é caracterizada pela arrumação contínua, formada pela união dos microagregados e plasma argiloso. 
Tabela 5: Percentuais de óxidos no solo, cal e misturas solo-cal.

\begin{tabular}{c|c|c|c|c|c}
\hline ÓXIDOS & CAL & SOLO & SOLO + 3\% CAL & SOLO + 5\% CAL & SOLO + 7\% CAL \\
\hline $\mathrm{SiO}_{2}$ & 0,00 & 39,45 & 37,91 & 37,51 & 36,80 \\
\hline $\mathrm{Al}_{2} \mathrm{O}_{3}$ & 1,50 & 21,17 & 20,51 & 20,28 & 19,95 \\
\hline $\mathrm{Fe}_{2} \mathrm{O}_{3}$ & 0,00 & 18,62 & 17,77 & 17,34 & 16,76 \\
\hline $\mathrm{MgO}$ & 1,93 & 1,28 & 1,25 & 1,27 & 1,28 \\
\hline $\mathrm{MnO}$ & 0,00 & 0,14 & 0,14 & 0,13 & 0,13 \\
\hline $\mathrm{CaO}$ & 66,42 & 0,14 & 1,47 & 2,73 & 4,30 \\
\hline $\mathrm{Na}_{2} \mathrm{O}$ & 0,00 & 0,00 & 0,00 & 0,00 & 0,00 \\
\hline $\mathrm{K}_{2} \mathrm{O}$ & 0,12 & 0,21 & 0,20 & 0,20 & 0,19 \\
\hline $\mathrm{TiO}_{2}$ & 0,06 & 4,74 & 4,49 & 4,40 & 4,24 \\
\hline $\mathrm{P}_{2} \mathrm{O}_{5}$ & 0,01 & 0,31 & 0,30 & 0,30 & 0,29 \\
\hline $\mathrm{PF}$ & 27,44 & 15,83 & 16,50 & 16,44 & 16,73 \\
\hline $\mathrm{Total}$ & 97,48 & 101,88 & 100,53 & 100,59 & 97,48 \\
\hline
\end{tabular}

As microestruturas das misturas solo-cal, apresentadas nas Figuras 7-b-c-d, mostram microagregados se comportando como grãos “pseudo siltes”, que acomodaram os grãos devido ao esforço aplicado, provocando entre si vazios. Há ocorrência de microporosidade, nas bordas dos microagregados, que não existe no solo natural e que resulta da ação da cal em contato com o plasma, semelhante ao que foi observado por [17, 21]. A microporosidade é consequência das reações da cal com o material do plasma provocando a neoformação de assembléia cristalina nas bordas dos microagregados preenchendo parcialmente os vazios. A adição da cal torna a microestrutura mais estável.
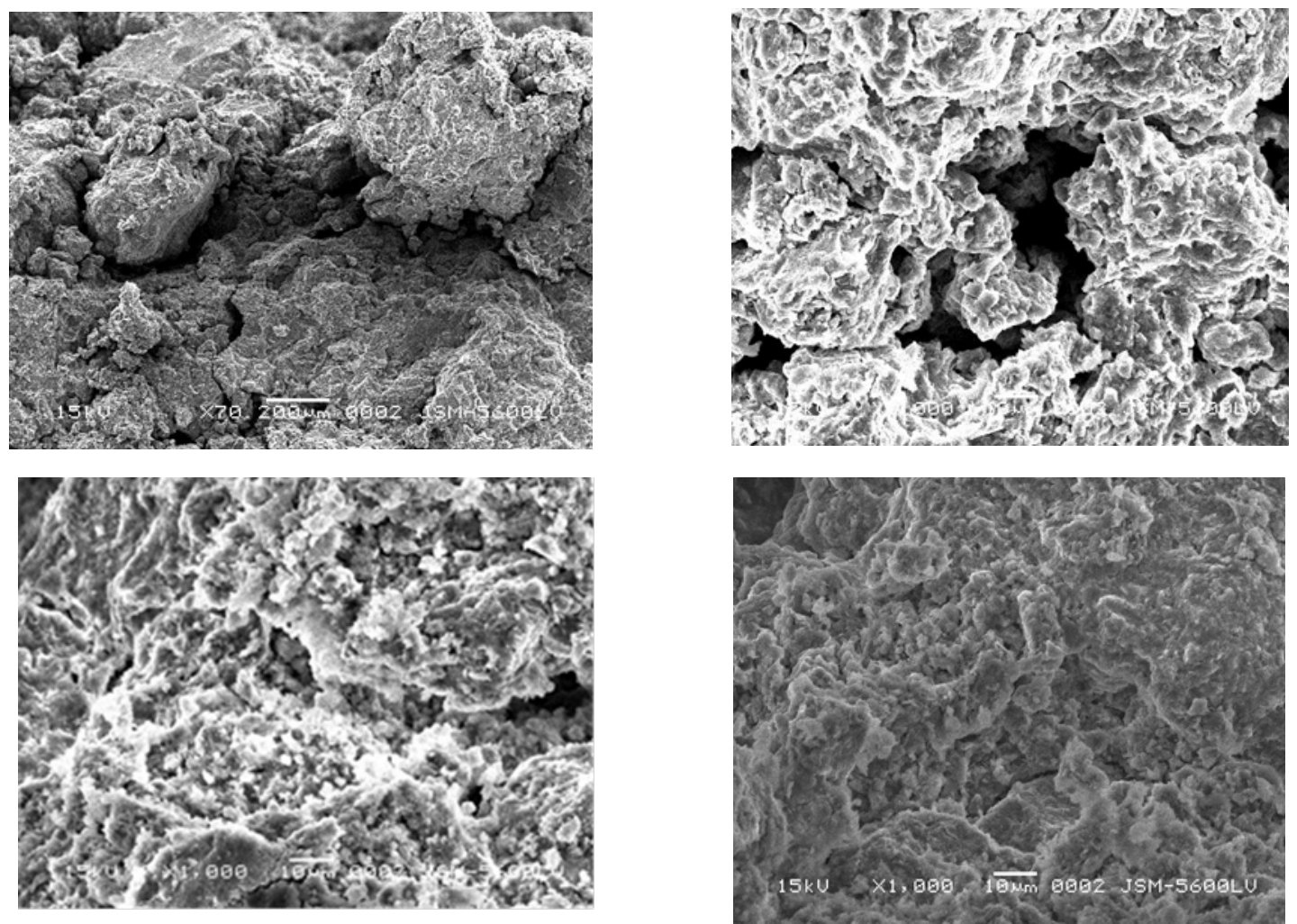

Figura 7: Elétron-micrografias a) solo natural compactado b) solo $+3 \%$ de cal c) solo $+5 \%$ de cal d) solo $+7 \%$ de cal.

\subsection{Caracterização Mineralógica}

A Figura 8 apresenta termogravimetria (TG) e diferencial termogravimétrico (DTG) da cal, do solo e das misturas solo-cal e os difractogramas de raios-X do solo. 
Na análise da TG/DTG da cal (Figura 8-a) admitiu-se que, aproximadamente, até $300^{\circ} \mathrm{C}$, perda de umidade (desidratação); entre a faixa de $300^{\circ} \mathrm{C}$ e $375^{\circ} \mathrm{C}\left(1^{\mathrm{a}}\right.$ inflexão) desidroxilação do hidróxido de magnésio; entre $375^{\circ} \mathrm{C}$ e $620^{\circ} \mathrm{C}\left(2^{\mathrm{a}}\right.$ inflexão) desidroxilação do hidróxido de cálcio; entre $620^{\circ} \mathrm{C}$ e $840^{\circ} \mathrm{C}\left(3^{\mathrm{a}}\right.$ inflexão) dissociação do carbonato de cálcio. Resultados similares foram encontrados por [41].

Na análise da TG/DTG do solo (Figura 8-b) entre $100^{\circ} \mathrm{C}$ até $250^{\circ} \mathrm{C}$ há um pico endotérmico intenso de perda de água; a $400^{\circ} \mathrm{C}$, inicia-se a reação de desidroxilação do hidróxido de esmectita que é completada a $700^{\circ} \mathrm{C}$. Os difratogramas de raios-X apresentados na Figura 8-c para o solo indicam que há uma interestratificação irregular envolvendo minerais do tipo 2:1 Mica e expansivos (esmectitas e vermiculitas) além da presença da Clorita.

Na análise da TG/DTG das misturas solo-cal com 3\%, 5\% e 7\% de cal são semelhantes as Figuras 8d-e-f respectivamente. Há um pico endotérmico intenso de perda de água até $220^{\circ} \mathrm{C}$; entre $250^{\circ} \mathrm{C}$ e $400^{\circ} \mathrm{C}$ acontece a desidroxilação do hidróxido de magnésio; entre $400^{\circ} \mathrm{C}$ e $600^{\circ} \mathrm{C}$ ocorre desidroxilação do hidróxido de cálcio; entre $600^{\circ} \mathrm{C}$ e $800^{\circ} \mathrm{C}$ há dissociação do carbonato de cálcio.

\subsection{Caracterização da Expansividade}

As expansões livres calculadas pela Eq 1 e obtidas a partir de ensaios edométricos convencionais com pequenas sobrecargas nas de tensões de $1 \mathrm{kPa}$ e $10 \mathrm{kPa}$ no solo natural são, respectivamente, 14\% e 12,00\%. Pelo critério de [42] (inundação a $10 \mathrm{kPa}$ ) o solo de Ipojuca-PE tem um grau de expansividade alto, de acordo com o critério de Cuellar [43]. Os valores da tensão de expansão do solo determinados com diferentes trajetórias de tensões, que correspondem a diferentes métodos, são apresentados na Figura 9. O valor médio obtido pelos três métodos foi $218 \mathrm{kPa}$ (Tabela 6), indicando que o solo pode causar danos nas edificações, quando umedecido, principalmente em obras de pequeno porte chegando a condição de demolição em acordo com o critério de [44]. A diferença fundamental entre os métodos é a ordem seguida entre a aplicação de tensão e a inundação. No Método-1, a amostra é inundada primeiro e carregada depois; no Método-2, a amostra é carregada primeiro e inundada depois; no Método-3, a inundação e carregamento ocorrem simultaneamente. As diferentes trajetórias de tensões aplicadas ao solo utilizadas nos métodos levam a valores distintos da tensão de expansão. Comportamento similar foi obtido por [45] na argila compactada Arahal-A coletada da Barreira La Paz de Arahal (Servillia), por [46] na argila de Petrolândia-PE e por[21] na argila de Cabrobó-PE, Tabela 6. Ao adicionar cal ao solo há diminuição da expansão livre (com pequena sobrecarga de $10 \mathrm{kPa}$ ) e da tensão de expansão (método do Volume Constante) como mostrado na Figura 10.

O valor de pH de 12,42 sugerido [16] foi obtido para 7\% de cal (Figura 6-a). Na mistura solo-cal com 7\% de adição de cal houve ainda expansão livre de 4,63\% (Figura 10a), tendo um grau de expansividade médio pelo critério de Cuellar [43] e uma tensão de expansão de 45 kPa (Figura 10b) indicando possibilidade de danos com pequenas fissuras nas edificações [44]. Assim o teor de 7\% de cal não foi suficiente para estabilizar a expansão do solo de Ipojuca-PE. Os valores do teor de cal para se atingir expansão livre e tensão de expansão nulos são respectivamente $11 \%$ e $9 \%$. Barbosa [21] verificou para o solo de Cabrobó-PE que o acréscimo 5\% de cal indicado pelo método de [16], estabilizou o solo também quanto à expansão livre e tensão de expansão, critério este que não foi verificado no solo de Ipojuca-PE. Isto pode ser explicado pelo fato do solo de Ipojuca-PE ter quantidade de cátions trocáveis de $\mathrm{Ca}^{2+}$ e $\mathrm{Al}^{3+}$ superiores ao do solo de Cabrobó-PE requerendo mais cal para estabilização. Além do mais, a expansão livre (14 \%) e a tensão de expansão (240 $\mathrm{kPa}$ ) do solo de Ipojuca-PE são superiores às do solo de Cabrobó-PE que tem valores de 7,45\% e $90 \mathrm{kPa}$ respectivamente. 

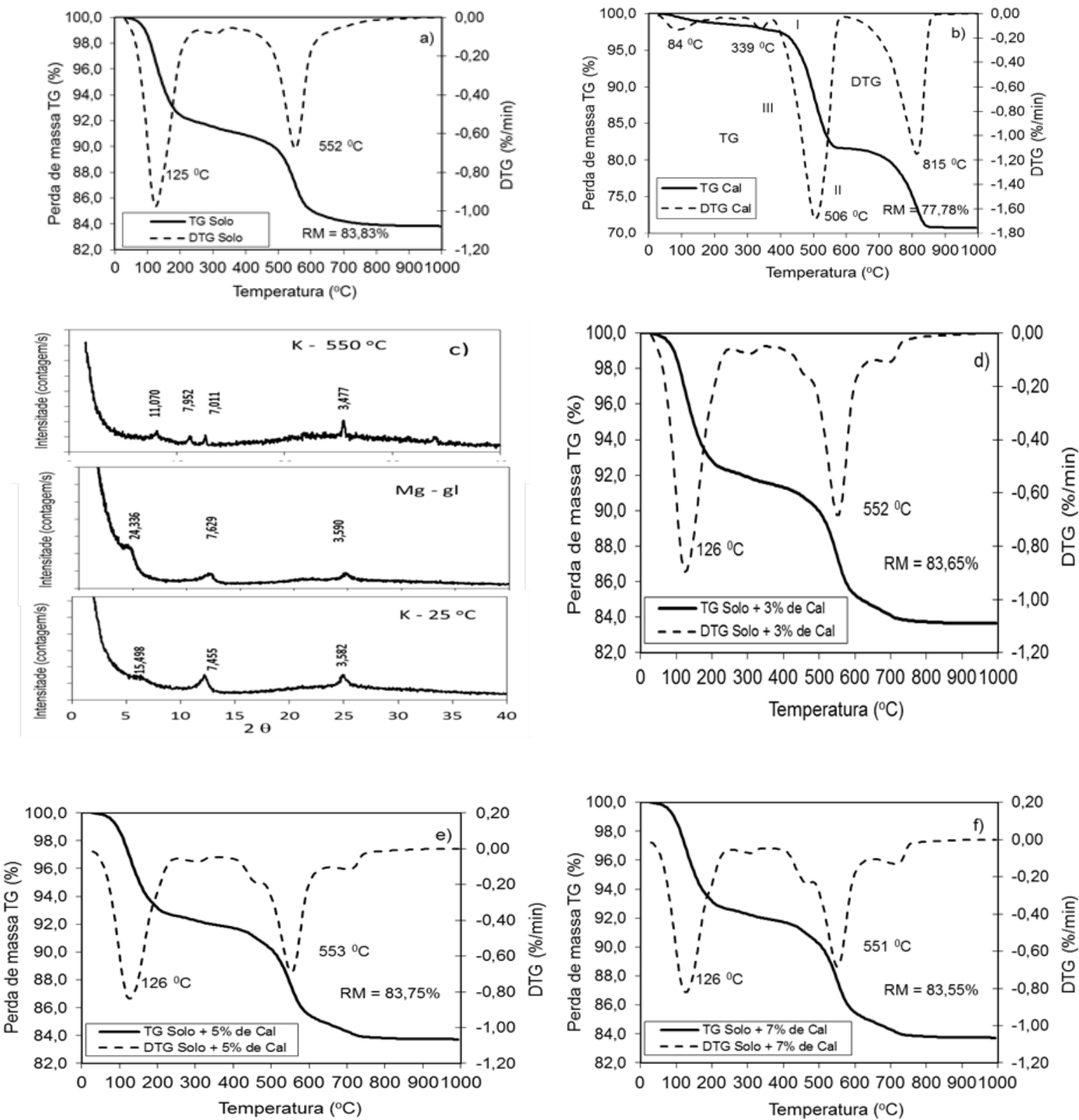

Figura 8: Curva TG e DTG: a) solo natural b) cal c) Difração de raio-X (d) solo + 3\% de cal e) solo + 5\% de cal, f) solo $+7 \%$ de cal.
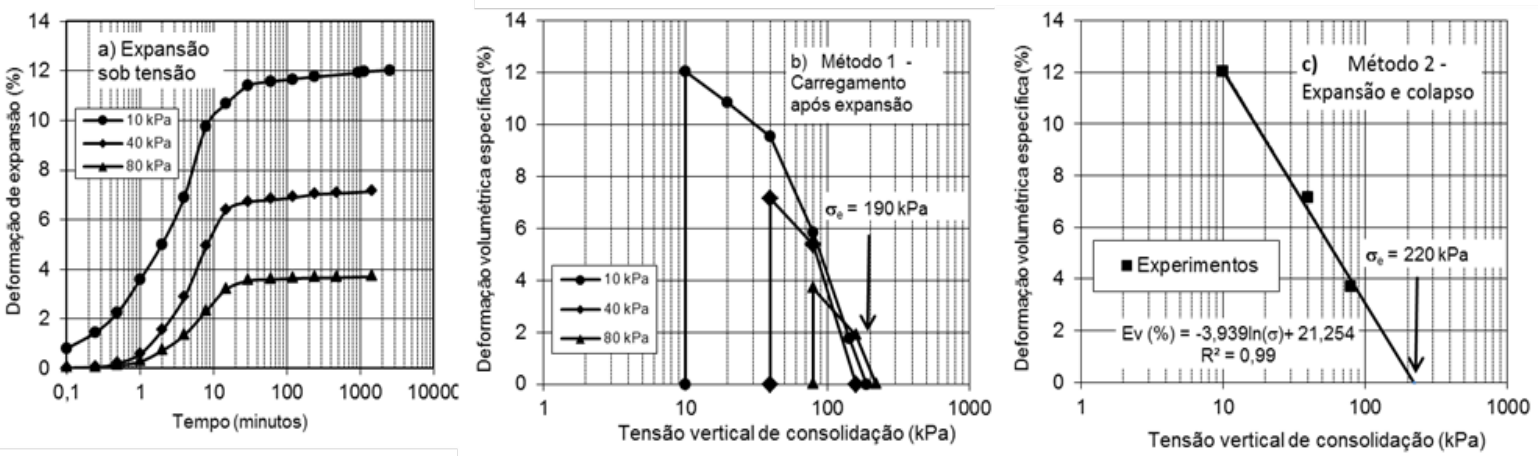

Figura 9: Métodos de tensão de expansão: a) Expansão sob tensão b) Método 1 - Carregamento após expansão com diferentes tensões verticais de consolidação c) Método 2 - Expansão e colapso. 
Tabela 6: Tensão de expansão.

\begin{tabular}{c|c|c|c|c}
\hline \multirow{2}{*}{ MÉTODO } & \multicolumn{4}{|c}{ TENSÃO DE EXPANSÃO (KPa) } \\
\cline { 2 - 5 } & $\begin{array}{c}\text { Argila de } \\
\text { Ipojuca }\end{array}$ & $\begin{array}{c}\text { Argila de } \\
\text { Sevilha [45] }\end{array}$ & $\begin{array}{c}\text { Argila de } \\
\text { Petrolândia [46] }\end{array}$ & $\begin{array}{c}\text { Argila de } \\
\text { Cabrobó [43] }\end{array}$ \\
\hline 1 & 190 & 260 & 333 & 90 \\
\hline 2 & 220 & 150 & 239 & 100 \\
\hline 3 & 245 & 193 & 242 & 87 \\
\hline Média & 218 & 201 & 271 & 92 \\
\hline
\end{tabular}
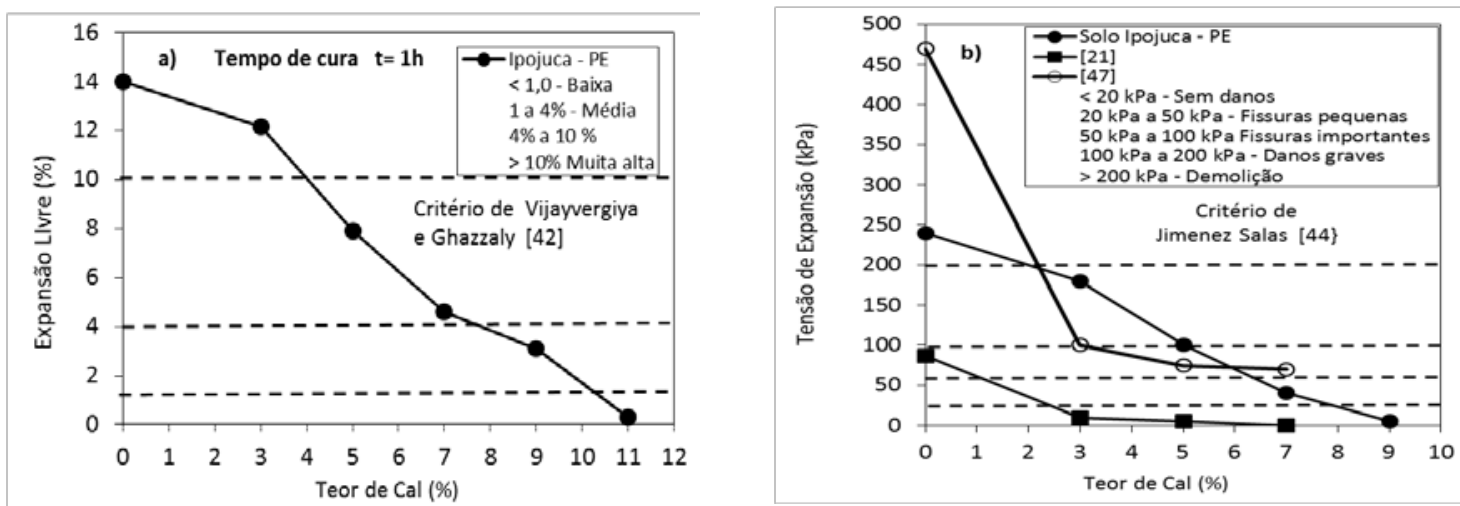

Figura 10: a) Variação da expansão livre com o teor de cal b) Variação de tensão de expansão com teor de cal

\section{CONCLUSÕES}

O solo de Ipojuca-PE tem alta expansividade, podendo apresentar danos às edificações levando à demolição, principalmente as de pequeno porte.

A determinação da tensão de expansão é influenciada pela trajetória de tensão seguida no ensaio.

O teor de cal de 7\% indicado pelo critério de Eades e Grim [16] não estabilizou o solo de Ipojuca-PE quanto a expansão livre e tensão de expansão, requerendo maior teor de cal (11\%).

A cal foi eficiente para reduzir a expansão livre e tensão de expansão do solo a valores nulos. Isto é atribuído à capacidade de cimentação do solo tratado com a cal que reduz a tendência de absorção de água das argilas saturadas com cálcio.

\section{AGRADECIMENTOS}

Os autores agradecem ao $\mathrm{CNPq}$ o suporte financeiro para o desenvolvimento da pesquisa.

\section{BIBLIOGRAFIA}

[1] NELSON, J.D., MILLER, D.J., Expansive soils: problems and practice in foundation and pavement engineering, New York, John Wiley \& Sons, 1992.

[2] DRISCOLL, R., CRILLY, M., Subsidence damage to domestic buildings, Lessons learned and questions asked, London, Building Research Establishment, 2000.

[3] AYALA CARCEDO, J.F., GIJON, M.F., MOZO, C.O., et al., Mapa previsor de riesgos por expansividad de argillas en España a Escala 1:1.000.000, In: Geologia Ambiental. Instituto Geologico y Minero de España, Centro de Estudios y Experimentacion de Obras Publicas, España, Madrid, 1986.

[4] SCHREINER, H.D., Volume change of compacted highly plastic African clays, Phd Thesis, Imperial College of Science and Technology, University of London, London, England, 1988.

[5] SOBRAL, H.S., Contribuição ao estudo de Massapê como solo para construção, Tese para Cátedra de Matérias de Construção, Universidade Federal da Bahia, Escola de Belas Artes, Salvador, BA, 1956.

[6] SIMMES, P.R.M., COSTA FILHO, L.M., "Características mineralógicas de solos expansivos do Recôncavo Baiano”, In: Simpósio Brasileiro de Solos Tropicais, pp.569-588, Rio de Janeiro, 1981. 
[7] COSTA NUNES, A.J., VASCONCELOS, E.M., PANDOLFI, R.M. "Ocorrências e propriedades de engenharia de solos expansivos na área do grande Recife”, In: Congresso Brasileiro de Mecânica dos Solos e Engenharia de Fundações, v.2, pp. 193-209, Olinda/Recife, 1982.

[8] VARGAS, M., “The concept of tropical Soils” In: Proceedings of the International Conference Geomechanics Tropical Lateritic And Saprolitic Soils,1, v.1, pp. 101-134, Brasília, 1985.

[9] GUSMÃO FILHO, J.A., SILVA, J.M.J., "Field instrumentation as related to an expansive soil”. In: Proceedings of the Panamerican Conference on Soil Mechanics and Foundation Engineering, 9. v.1 pp. 7686, Viña Del Mar, 1991.

[10] FERREIRA, S.R.M., “Solos colapsíveis e expansivos: uma visão panorâmica no Brasil”. In: Simpósio Brasileiro De Solos Não Saturados, 7, v.2. pp. 593- 619, Salvador, 2008.

[11] AMORIM, S.A., Contribuição à cartografia geotécnica: sistema de informações geográfica dos solos colapsíveis e expansivos do estado de Pernambuco, Dissertação de M.Sc., Universidade Federal de Pernambuco, Recife, 204p, 2004,

[12] FERREIRA, S.R.M., AMORIM, S.F., VAREJAO-SILVA, M.A. “Tecnologia da geoinformação aplicada aos estudos dos solos expansivos e colapsíveis do estado de Pernambuco”, In: Simpósio Brasileiro de Ciência Geodésicas e Tecnologias de Geoinformação, 2, v.1. p. 91-99, Recife, 2008.

[13] BRANDL, H. “Alteration of soil parameters by stabilization with lime”, In: Proceedings of the International Conference on Soil Mechanics on Foundation Engeneering, 10., v.1, pp.587-595.. Stockholm, 1981.

[14] LOCAT, J., TREMBLAY, H., LEROUEIL, S., "Mechanical and hydraulic behavior of a soft inorganic clay treated with lime”, Canadian Geotechnical Journal, v.33, n. 4, pp. 654-669, 1996.

[15] SIVAPULLAIAH, P.V., LAKSHMI, KANTHA H., KORUKONDA, M.K., "Geotechnical properties of stabilized Indian red earth”, Geotechnical and Geological Engineering, n.21, pp. 399 - 413, 2003.

[16] EADES, J.L., GRIM, R.E., A quick test to determine lime requirements for lime stabilization. In: Highway Research Record, Washington, D.C., n. 139, pp.61-72, 1966.

[17] NÓBREGA, M.T., “Estabilização Solo-Cal”, In: Associação Brasileira dos Produtores de Cal, Boletim 13, São Paulo, Brasil, 1981.

[18] AL-RAWAS, A.A., GOOSEN, M.F.A. Expansive soils: recent advances in characterization and treatment, London, Taylor \& Francis group/Balkema, 2006.

[19] AL-MUKHTAR, M., LASLEDJ, A., ALCOVER, J.F., "Behaviour and mineralogy changes in limetreated expansive soil at 20C”, Applied Clay Science, v. 50, pp. 191-198, 2010.

[20] CUISINIER, O., AURIOL, J.C., LEBORGNE, T., et al., "Microstructure and hydraulic conductivity of a compacted lime-treated soil”, Engineering Geology, v.123, n.3, pp. 187-193. 2011.

[21] BARBOSA, V. Estudo do comportamento geotécnico de um solo argiloso de Cabrobó, potencialmente expansivo, estabilizado com cal, Dissertação de MSc, Universidade Federal de Pernambuco, Recife, PE, $115 p, 2013$.

[22] BELL, F.G., “Lime stabilization of clay minerals and soils”, Engineering Geology, v. 42, n. 4, pp. 223237, 1996.

[23] ABNT. “ABNT/NBR 7175: cal hidratada para argamassas - requisitos”, Rio de Janeiro, ABNT, 2003.

[24] ABNT. “ABNT/NBR 6473: cal virgem e cal hidratada - Análise química”, Rio de Janeiro, ABNT, 2003.

[25] ABNT. “ABNT/NBR 9290: cal hidratada para argamassas - determinação de retenção de água”, Rio de Janeiro, ABNT, 1996.

[26] ABNT. “ABNT/NBR 9289: cal hidratada para argamassas - determinação da finura”, Rio de Janeiro, ABNT, 1998.

[27] ABNT. “ABNT/ NBR 6457: amostras de solo - preparação para ensaios de compactação e ensaios de caracterização. Rio de Janeiro”, 1986.

[28] ABNT. “ABNT/ NBR 7182: solo - ensaio de compactação - procedimento”. Rio de Janeiro, ABNT, 1986. $10 \mathrm{p}$.

[29] ABNT. “ABNT/ NBR 6459: solo - determinação do limite de liquidez - procedimento”. Rio de Janeiro, ABNT, 1984. 6 p. 
[30] ABNT. “ABNT/ NBR 7180: solo - determinação do limite de plasticidade - procedimento”. Rio de Janeiro, ABNT, 1984. 6 p.

[31] ABNT. “ABNT/ NBR 6508: solo - grãos de solo que passam na peneira de 4,8 mm: determinação da massa especifica”. Rio de Janeiro, ABNT, 1984.

[32] ABNT. “ABNT/ NBR 7181: solo - análise granulométrica - procedimento”. Rio de Janeiro, ABNT, 1984.

[33] EMBRAPA, Sistema brasileiro de classificação de solos, In: Empresa Brasileira de Pesquisa Agropecuária, Centro Nacional de Pesquisa de Solos, Embrapa Serviço de Produção de Informação, Brasília, 212 p. 1997.

[34] EMBRAPA, Sistema brasileiro de classificação de solos, In: Empresa Brasileira de Pesquisa Agropecuária, Centro Nacional de Pesquisa de Solos, Embrapa Serviço de Produção de Informação, Brasília, 412 p. 1999.

[35] JACKSON, M.L., Soil chemical analysis - Advanced course, Madison, Prentice-Hall, 1979.

[36] FERREIRA, S.R.M., Colapso e expansão de solos naturais não saturados devidos à inundação, Tese de D.Sc., COPPE/UFRJ, Rio de Janeiro, RJ, 1995.

[37] SKEMPTON, A.W. The colloidal activity of clays, In: Proceedings of the International Conference on Soil Mechanics on Foundation Engeneering, 3. v.1, pp.587-595, London, 1953

[38] SEED, H.B., WOODWARD, R.J., LUNDGREN, R. "Prediction of swelling potencial for compacted clays”. Journal Soil Mechanics and Foundations Division, ASCE, v. 88, SM3, pp. 53-87, 1962.

[39] DAKSANAMURTY, V. RAMAN, V. “A simple method of identifying an expansive soil”. Soils and Foundation, v.13, n. 1 pp. 97-104, 1973.

[40] LITTLE, D.N., Handbook for stabilization of pavement subgrades and base courses with lime, Iowa, Kendall/Hunt Publishing Company, 1995.

[41] CINCOTTO, M.A., Estudo da composição Química da cal hidratada. In: Associação Brasileira dos Produtores de Cal, Boletim 11, pp. 67-94, São Paulo, Brasil, 1980.

[42] VIJAYVERGIYA, V.N., GHAZZALY, O.I., "Prediction of Swelling Potential for Natural Clays”, In: Proceedings of the International Conference on Expansive Soils 3. v. 1, pp. 227 - 236, Hayfa, 1973.

[43] CUELLAR, V. “Analisis crítico de los métodos existentes para el empleo de arcillas expansives en obras de carreteras y recomendaciones sobre las técnicas más idóneas para su uso habitual em España”. In: Laboratório del Transposte y Mecánica del Suelo, 303p., 1978.

[44] JIMENEZ SALAS, J.A., Cimentationes en terrenos expansivos o colasables, In: Geotecnia y Cimientos III, v.1, pp. 533-650, Ed. Rueda, Madrid, 1980.

[45] DELGADO, A., Influencia de la trayectoria de las tensiones en el comportamiento de las Arcillas expansivas y de los suelos colapsables en el laboratorio y en el terreno, Tesis Doctoral, Universidad de Sevillia, Espanha 1986.

[46] FERREIRA, S.R.M., FERREIRA, M.G.V.X., "Mudanças de volume devido à variação do teor de umidade em um vertissolo no Semi-Árido de Pernambuco”, Revista Brasileira de Ciência do Solo, v. 33, pp. 779-791, 2009.

[47] NALBANTOGLU, Z., "Lime stabilization of expansive clay”, In: AL-Rawas, A.A., Goosen, M.F.A. (eds), Expansive soils: recent advances in characterization and treatment, chapter 23, London, England, Taylor \& Francis group/Balkema, 2006. 